\title{
High Mechanical Performance of Reinforced Concrete Wrapped with Carbon-Fiber Polymer and Electrochemical Corrosion Behavior of Carbon Steel in the concrete
}

\author{
Liang Liu*, Haihua Yang \\ College of Water Conservancy and Civil Engineering, Xinjiang Agricultural University, Urumqi \\ 830052, China \\ *E-mail: Liuhualiang1978@ sina.com
}

doi: $10.20964 / 2020.10 .55$

Received: 20 June 2020 / Accepted: 3 August 2020 / Published: 31 August 2020

\begin{abstract}
One of the solutions proposed by researchers to control the corrosion of reinforced concrete is the use of wrapping technology. Many researchers have investigated carbon-fiber polymer (CFP) for the aim of wrapping reinforced concrete. However, the effect of using CFP on the corrosion resistance of concretes has not been fully studied by researchers. This work focused on the mechanical performance and electrochemical corrosion behavior of carbon steel reinforced concrete wrapped with CFP. The samples were made with one, two, and three CFP layers and tested for corrosion resistance. The orientation of wrapped CFP has also been studied in this work. The results indicated that the compressive strength of the concrete cube samples increased by increasing the CFP layers. Electrochemical impedance spectroscopy tests indicated that the reinforced concrete wrapped with CFP had a higher value of passive film resistance compared to plain concrete, indicating more enhancement of corrosion resistance on the surface of carbon steel rebar.
\end{abstract}

Keywords: Carbon-fiber polymer; Reinforced concrete, Electrochemical corrosion; Compressive strength

\section{FULL TEXT}

(C) 2020 The Authors. Published by ESG (www.electrochemsci.org). This article is an open access article distributed under the terms and conditions of the Creative Commons Attribution license (http://creativecommons.org/licenses/by/4.0/). 